\title{
A produção de conhecimento sobre formação inicial e currículo em Educação Física no Brasil
}

http://dx.doi.org/10.11606/1807-5509201900020241

\author{
Juliana PIZANI* \\ Fabiane Castilho TEIXEIRA ${ }^{* * * * *}$ \\ Amauri Aparecido Bássoli de OLIVEIRA**/*** \\ Ieda Parra BARBOSA-RINALDI**/*** \\ *Departamento de \\ Educação Física, \\ Universidade Federal \\ de Santa Catarina, \\ Florianópolis, SC, \\ Brasil. \\ ${ }^{* *}$ Centro de Educação \\ Física e Esporte, \\ Universidade Estadual \\ de Londrina, Londrina, \\ PR, Brasil. \\ ${ }_{* * * \text { Departamento de }}$ \\ Educação Física, \\ Universidade Estadual \\ de Maringá, Maringá, \\ $\mathrm{PR}$, Brasil.
}

\section{Resumo}

Esta pesquisa bibliográfica objetivou analisar a produção de conhecimento por meio de teses e dissertações sobre formação inicial e currículo em Educação Física no período de 1980 a 2012, com vistas ao mapeamento das características metodológicas, bem como das proposições para o cenário formativo. A amostra contou com 47 trabalhos, sendo 15 teses e 32 dissertações, que foram tratadas por meio de estatística descritiva e análise de conteúdo. Estas pesquisas representam apenas 2\% da amostra total de teses e dissertações. Verificou-se que a abordagem qualitativa, estudo de caso e as pesquisas descritiva, documental, foram utilizadas com maior frequência. Os resultados ainda indicam que $83 \%$ das pesquisas são não-propositivas e 17\% propositivas, sendo estas representadas por duas categorias: orientação técnica e pedagógica e organização curricular. Concluímos que há necessidade de desenvolvimento de teses e dissertações que foquem a formação inicial e currículo, especialmente ao considerar as mudanças curriculares e seu impacto para a área como um todo, bem como destacamos a importância da produção científica com caráter propositivo para a área da Educação Física.

PalavRAS-Chave: Graduação; Conhecimento; Pesquisa; Metodologia.

\section{Introdução}

O recorte desse estudo centra-se na análise da produção de conhecimento (estado da arte) sobre formação inicial e currículo em Educação Física, tendo como foco teses e dissertaçóes produzidas desde a década de 1980 em programas de pósgraduação (PPG) da área, haja vista que a partir desse período os pesquisadores voltaram a atenção para a constituiçáo do currículo no âmbito da Educação Física.

Com a aceleração do processo de globalização, nas décadas de 1980 e 1990, marcado pela abertura do país ao mercado internacional acentua-se a valorização da formação de recursos humanos qualificados paro o mercado de trabalho e a formação nas universidades é reconhecida como meio de articulação para as demandas sociais então instituídas.

Foi neste cenário de mudanças e reorganização social que os debates sobre o currículo se intensificaram no Brasil. A Educação Física como área de formação é veiculada a intensas discussôes sobre a necessidade de reestruturação curricular, já que até então, os conteúdos desenvolvidos no currículo não eram focalizados. Além disso, destacamos às preocupações com os métodos que vinham sendo utilizados pelos professores para o ensino dos seus conteúdos. A formação inicial, é então, reconfigurada. 
$\mathrm{Na}$ produção teórica analisada, encontramos pesquisadores de fato preocupados com os rumos da formação e o papel da estrutura curricular neste processo, a exemplo das pesquisas das dissertaçóes desenvolvidas por Verenguer ${ }^{1}$; Anderáos ${ }^{2}$; Barbosa-Rinaldi ${ }^{3}$; Moreira ${ }^{4}$; Schwarz ${ }^{5}$; Brugnerotto $^{6}$; Carvalho $^{7}$; Pizani ${ }^{8}$. E das teses desenvolvidas por Ramos ${ }^{9}$; ANDERÁOs ${ }^{10}$; BarbosaRINALDI ${ }^{11}$; SouZA ${ }^{12}$; ANTUNES ${ }^{13}$.

Os pesquisadores centraram foco no processo formativo ofertado pelas instituiçóes de ensino superior. Além da preocupação com os aspectos normativos que regiam os cursos, as pesquisas apresentam debates produtivos sobre as estruturas curriculares executadas por instituiçôes, com vistas a identificação de como organizam e desenvolvem seus conteúdos e metodologias. Apontam ainda, pontos fortes e frágeis da formação averiguada, que carecem de atenção por parte da comunidade científica como um todo.

Vale destacar que historicamente, a Educação Física, como área de conhecimento, pode ser observada em diversos âmbitos, apresentando diferentes intencionalidades. No universo da prática científica os questionamentos precisam ser invariavelmente feitos, já que instituem a oportuna reflexão epistemológica, a qual possibilita que os pesquisadores conheçam a natureza do conhecimento que manipulam ${ }^{14}$.

De acordo com Bracht et al. ${ }^{15}$, é na década de 1980 que o campo acadêmico da Educação Física se destaca, especialmente pela consolidação da pósgraduação stricto sensu. Isso porque, foram criados sete programas de pós-graduação entre os anos de 1977 a 1989 e seis na década de 1990. Atualmente, contamos com 29 cursos de mestrado, sendo um deles mestrado profissional e 18 de doutorado.

Entretanto, podemos aferir que, a produção do conhecimento em Educação Física foi impulsionada a partir do final da década de 1970 com a criação do primeiro curso de mestrado stricto sensu no Brasil. Até então, segundo DAOLIo ${ }^{16}$, era comum o entendimento de que a Educação Física se preocupava apenas com a prática escolar que tinha por objetivo o desenvolvimento da aptidão física dos alunos, bem como iniciá-los na prática desportiva. Mesmo porque, esse era o ditame legal estabelecido para o momento pela Lei n. 5.692/71 ${ }^{17}$ que estabelecia a Educaçáo Física como atividade no meio escolar.

Esse cenário estabeleceu uma constante preocupação com a caracterização da Educação Física como campo de conhecimento acadêmico e profissional, vinculada à necessidade de justificar sua presença no ensino superior, bem como seu reconhecimento social. Assim, consolidar a área no âmbito acadêmico, significa estar comprometida, também, com as demandas sociais, apontando a importância da produçáo do conhecimento ao dar suporte à realidade profissional cotidiana.

LüDORF ${ }^{18}$ destaca que com o passar do tempo, novos programas de pós-graduação foram criados, $\mathrm{o}$ que fez crescer gradativamente a produção científica da área, contribuindo para um processo de reflexão, amplitude e aprimoramento do campo de estudos que abrange a Educação Física. Desse modo, é incontestável que a Educação Física no Brasil tenha tido um sensível avanço com o crescimento dos cursos de pós-graduação em nível de mestrado e doutorado, o que pode ser observado em Souza e Silva ${ }^{19,20}$.

A universidade historicamente teve a responsabilidade pela produção de conhecimento e com o advento da pós-graduação amplia essa função. Nesse sentido, os integrantes dessa modalidade de formação carregam consigo a responsabilidade dessa produção de conhecimentos que se expressam por meio de dissertaçóes e teses, além de inúmeros artigos resultantes destes trabalhos.

Sobre o contexto da produção de conhecimento, KoKUBUN $^{21}$ alerta que este requer um sólido sistema de pesquisa e desenvolvimento, bem como um corpo de pesquisadores preparados para se responsabilizar pelas pesquisas. O processo de formação na pósgraduação ocorre paralelamente à produçáo de novos conhecimentos que é potencializado pelo engajamento discente (futuros mestres e doutores). Tratando da temática Вотоме́ е Киво ${ }^{22}$ defendem que o papel da pós-graduação no Brasil está entrelaçado às suas responsabilidades sociais, e as instituiçóes de ensino superior precisam produzir conhecimento necessário para o desenvolvimento social.

Mediante o acelerado desenvolvimento da produção científica, resultado do crescimento dos cursos de graduação e pós-graduação, a produção do conhecimento na área da Educação Física tem sido foco de diversos estudos, tais como CarLan ${ }^{23}$, KoKubun $^{21}$, Lüdorf ${ }^{18}$, Molina Neto et al. ${ }^{24}$, Bracht et al. ${ }^{15}$, entre outros. Os estudos em sua maioria apresentam uma preocupação com o que vem sendo produzido na área, tomando por foco diferentes eixos temáticos. Nesse sentido, se faz necessário que a área pense sobre sua própria produção, bem como busque a compreensão das lacunas teóricas existentes nesse campo de atuação. Ressaltamos, porém, que mesmo tendo ciência do boom do produtivismo acadêmico, não temos como 
objetivo analisar a qualidade da produção, mas sim o que se tem produzido no panorama da formação inicial e currículo.

Assim, considerando a importância de ampliação de pesquisas que enfoquem a temática e buscando fomentar discussóes acerca da produção do conhecimento na área da Educaçáo Física, em especial, no contexto do ensino superior, elegemos as seguintes questóes norteadoras: Como tem se caracterizado a produção de conhecimento sobre formação inicial e currículo em Educação Física? Essa produção de conhecimento tem apresentado propostas de intervenção para a área da Educação Física?

Dessa forma, definimos como objetivo geral da pesquisa: analisar a produção de conhecimento por meio de teses e dissertaçôes sobre formaçáo inicial e currículo em Educação Física no período de 1980 a
2012, com vistas ao mapeamento das características metodológicas, bem como das proposiçóes para o cenário formativo. Para tanto, foi necessário: mapear o fluxo e volume da produção de conhecimento de teses e dissertaçóes sobre formação inicial e currículo no período de 1980 a 2012; elaborar um banco de dados de teses e dissertaçóes que abordam o tema formação inicial e currículo; apresentar um quadro geral das características metodológicas utilizadas para a elaboração das teses e dissertaçôes; categorizar as teses e dissertaçóes em propositivas e não propositivas.

A pesquisa tornou-se relevante no sentido, não somente de diagnosticar o que vem sendo produzido nos programas de pós-graduação stricto sensu, mas por oferecer dados para discutir a produção de conhecimento, além de fornecer uma base de consulta do que já foi produzido.

\section{Método}

Elegemos para esta investigação a pesquisa bibliográfica, que segundo Trujillo Ferrari ${ }^{25}$ tem por finalidade " $[. .$.$] conhecer as contribuiçóes$ científicas que se efetuaram sobre determinado assunto" (p. 209) ou mapear a produção de conhecimento em relaçáo a um determinado tema.

Com o objetivo de definir a amostra do estudo, num primeiro momento, fizemos um levantamento das Instituiçóes de Ensino Superior que oferecem cursos de pós-graduação em nível de mestrado e/ou doutorado na área da Educação Física, totalizando de acordo com a Coordenaçáo de Aperfeiçoamento de Pessoal de Nível Superior na grande área das Ciências da Saúde, área da Educação Física, 29 instituições.

A escolha por investigar os programas de pósgraduação da área da Educação Física justifica-se pelo objetivo em analisar pesquisas com temáticas específicas da área em questão, bem como ter a compreensão do que vem sendo produzido internamente, haja vista que, desde a década de 1980 a área tem buscado se legitimar pedagogicamente e socialmente.

Em seguida, selecionamos os programas de pós-graduação participantes da pesquisa a partir dos critérios: 1) oferecer o curso de mestrado e/ou doutorado acadêmico em Educação Física; 2) ser curso recomendado e reconhecido pela Capes; e 3) disponibilizar as teses e dissertaçôes online no site do programa de pós-graduação e/ou no Portal Domínio Público; 4) disponibilizar as dissertaçóes e teses completas e/ou contendo título, nome do autor, ano e resumo; 5) conter no mínimo 10 dissertaçóes e/ou teses por programa.

Informamos que, pelo fato de nem todos os programas disponibilizarem ferramenta de busca, não pudemos utilizar palavras-chave e/ou descritores. Sendo necessário a elaboraçáo de um banco de dados com todas as pesquisas encontradas, organizado de forma cronológica de acordo com o ano de publicação dos trabalhos, contendo informações como autor, ano, título e instituição, para somente depois identificarmos as pesquisas que abordam o tema da Educação Física escolar. Dos 29 programas de pós-graduação existentes, apenas 14 programas atenderam aos critérios estabelecidos, totalizando, 2351 trabalhos selecionados para análise (386 teses e 1965 dissertaçóes).

Para realizar a seleção da amostra sobre formação inicial e currículo recorrermos à ferramenta "Localizar" do Excel, em que utilizamos as palavraschave "formação" e "currículo" presentes nos títulos das teses e dissertaçôes. Nessa primeira triagem mapeamos 102 teses e dissertaçôes, sendo 28 teses e 74 dissertaçóes.

$\mathrm{Na}$ sequência realizamos a leitura do título, resumo e introdução para verificar quais pesquisas tratavam da temática formaçáo inicial e currículo de forma conjunta. Dessa forma, tivemos uma reduçáo para 48 pesquisas (16 teses e 32 dissertações), as quais representam apenas $2 \%$ da amostra total do banco de dados. Ainda vale destacar que, apenas 8 dos 14 programas de pós-graduaçáo que compóem o banco de dados possuem trabalhos 
que abordam o tema em questão: UNICAMP (28), UFSC (7), USJT (2), UNIMEP (1), UNESPRC (3), UFPEL (2), UEM-UEL (3) e USP (2).

Estas teses e dissertaçôes constituem o banco de dados da produçáo de conhecimento sobre formação inicial e currículo no cenário nacional da Educação Física. A escolha por pesquisar teses e dissertaçóes é por entender que nem todas sáo veiculadas em periódicos ou livros.

Para a análise do estado da arte, tendo como finalidade a categorização das produçóes pesquisadas, bem como sua quantificação, recorremos à estatística descritiva e à técnica de análise de conteúdo proposta por BARDIN ${ }^{26}$, a fim organizar os dados e qualificar a interpretação dos resultados, sendo entendida "como um conjunto de técnicas de análise das comunicaçóes, que utiliza procedimentos sistemáticos e objetivos de descrição do conteúdo das mensagens" (p. 38).

Após a seleção da amostra final, partirmos para uma próxima etapa do tratamento dos dados, em que exigiu a leitura completa das pesquisas. Sendo assim, dividimos a análise em dois momentos: o primeiro centrou-se no mapeamento do fluxo e volume da produção no período de 198012012 e na categorização das características metodológicas utilizadas para a elaboraçáo das teses e dissertaçôes, por meio da análise da metodologia exposta, tendo como referência a classificação proposta por $\mathrm{GIL}^{27}$; e o segundo objetivou classificar as teses e dissertaçóes em propositivas e não propositivas.

\section{Resultados e Discussão}

Tendo como base as teses e dissertações produzidas nos programas de pós-graduação em Educação Física, indicamos como resultados um panorama da produçáo de conhecimento sobre formação inicial e currículo, tanto no que diz respeito ao fluxo e volume dessa produção, quanto à sua caracterização metodológica e identificação das propostas formuladas. A discussão toma como base essas três análises realizadas e que retratam como a temática vem sendo pensada no contexto da Educação Física.

Nessa direção, os resultados da investigação, abordados a partir da descriçáo dos dados coletados, indicam um panorama da produção de conhecimento sobre formação inicial e currículo na área da Educação Física sob a ótica das teses e dissertaçóes. Os dados são discutidos a partir do referencial que sustenta o estudo.
Na FIGURA 1 nos reportamos à análise do fluxo e do volume da produçáo de teses e dissertaçóes por ano. É importante ressaltar que os programas de pósgraduação foram se consolidando aos poucos e em épocas diferentes, portanto, não são em todos os anos que estão presentes todos os programas que fizeram parte da pesquisa, visto que alguns surgiram mais recentemente. Ainda destacamos que não tivemos acesso às pesquisas vinculadas aos PPGs que não se encontram mais em funcionamento.

Vale ressaltar que somente dois programas fizeram parte da amostra em produção de teses, o que sugere que a temática não vem sendo tratada em todos os PPGs, além do fato de que até 1999 apenas um PPG apresentou dissertações abordando a temática.

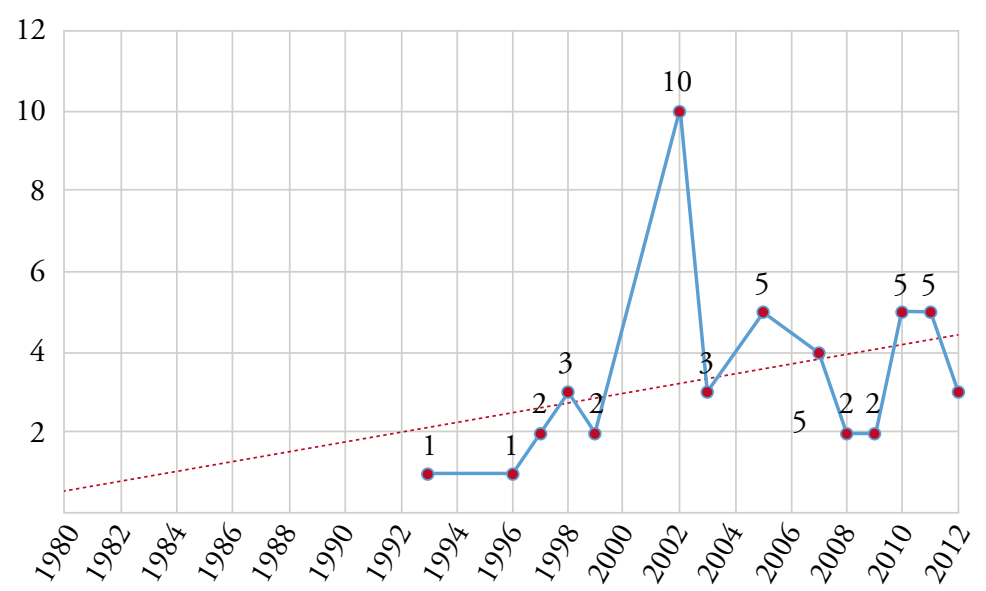

FIGURA 1 - Quantificação do fluxo e do volume da produção de conhecimento de teses e dissertações sobre formação inicial e currículo no período de 1980 a 2012. 
Analisando o FIGURA 1, podemos notar que a primeira pesquisa que tratou do tema formação inicial e currículo foi finalizada somente em 1993, embora, nosso recorte temporal tenha se dado a partir de 1980.

Observamos também que, o ápice do crescimento se deu no ano de 2002, tendo como resultado 10 teses e dissertaçóes, representando um período de efervescência nas discussóes da área, que passava por modificações nas diretrizes curriculares nacionais, e que determinariam a obrigatoriedade de currículos próprios para os cursos de licenciatura, por meio das ResoluçóEs CNE/CP n. $01^{28}$ e 02/2002 ${ }^{29}$. A partir deste ano a linha de tendência também apresentou um crescimento contínuo, recebendo uma queda no quantitativo em 2008 e 2009. O acréscimo do número de dissertaçóes e teses pode ser explicado em virtude de um maior investimento na pós-graduação brasileira, assim como do aumento do quantitativo de programas de pós-graduação em Educação Física no Brasil.

Chegamos a esta análise ao considerar que o incentivo financeiro cresceu, tanto em relação a fomentos para realização de pesquisas como no caso de bolsas para mestrado e doutorado (crescendo de 221 em 2005 para 898 bolsas em 2012 para a área da Educação Física) (Capes) ${ }^{30}$.

Cabe salientar que, por possível ausência de atualização nos sites dos PPGs, o número de pesquisas nos anos de 2010, 2011 e 2012 pode ser maior do que o encontrado nos dados.

Como parte da investigação também foram elencados os tipos de pesquisas descritas nas teses e dissertações pesquisadas. Num primeiro momento identificou-se o tipo de abordagem assumida (qualitativa e quantitativa). Após, organizamos os dados de acordo com a classificação apresentada por $\mathrm{GIL}^{27}$, em que traz as possibilidades metodológicas considerando os: objetivos (exploratória, descritiva e explicativa); e procedimentos técnicos (pesquisa bibliográfica, documental, experimental, ex-postfacto, estudo de coorte, levantamento, estudo de campo, estudo de caso, pesquisa-ação e pesquisa participante).

Dentre as 48 teses e dissertaçóes pesquisadas identificou-se que 22 dissertaçóes (46\%) e 10 teses $(21 \%)$ delas indicaram utilizar a abordagem qualitativa e $33 \%$ não fizeram menção a nenhuma outra abordagem. Salientamos que a abordagem quantitativa não foi citada nos trabalhos pesquisados.

Encontramos resultados semelhantes em um estudo desenvolvido por Gomes et al. ${ }^{31}$ cujo objetivo foi cartografar a tipologia de estudos empíricos realizados acerca da identidade profissional do professor, no qual evidenciaram um predomínio de estudos de natureza qualitativa.

BeTtI $^{32}$ justifica que a inserção das pesquisas qualitativas na Educação Física a partir do final do século XX e início do XXI, sob a influência da pedagogia, assume papel importante para este campo de conhecimento, inicialmente com estudos de inspiração etnográfica.

No tocante a pesquisa qualitativa, Bogdan e BIKLEN $^{33}$ informam que esta tem ganhado destaque na educação, principalmente a partir da década de 1960, provavelmente por possuir características apropriadas para a área, como: a fonte direta de dados é o ambiente natural; o investigador é o instrumento principal; não privilegia os resultados em detrimento dos processos; a análise dos dados ocorre de forma indutiva; e tem caráter descritivo.

Ressaltamos que na abordagem qualitativa, a realidade não é externa ao sujeito, e, portanto, o conteúdo interpretativo é destacado por THOMAs e $\mathrm{Nelson}^{34}$ como sendo uma das características mais significativas da pesquisa qualitativa ao invés da preocupação excessiva com o procedimento. A ênfase dada à interpretaçáo pelo pesquisador permite compreender o tema abordado com mais exatidão, no entanto, constitui-se também uma limitação da pesquisa, pois se refere à capacidade e conhecimento do investigador em articular o referencial teórico com os dados coletados, atribuindo aos fatos um caráter analítico, de maneira que não cabe ao pesquisador apenas descrevê-los como tais se encontram. Assim, os resultados recebem influência de quem os interpretam. Como bem observa ANDRÉ Bj $^{5}$, "a orientação teórica do pesquisador, suas experiências anteriores, seu grau de imersão nos dados, seus valores, suas crenças e perspectivas podem orientar o foco de investigação para aspectos mais concretos ou concepçôes mais abstratas" (p. 68).

Contudo, faz-se necessário discutir a necessidade de superação da dicotomia qualitativo/quantitativo. Nesse sentido, ANDrÉ ${ }^{36}$ tece uma crítica sobre a concepção disseminada de que a pesquisa qualitativa é simplesmente aquela que não usa dados numéricos e, ainda, que associar quantificação ao positivismo é perder de vista que os dois paradigmas estão intimamente relacionados. A autora destaca que este entendimento tem gerado equívocos, especialmente no que tange a oposição entre qualitativo versus quantitativo, e salienta que não se trata de termos dicotômicos, sugerindo a utilização de denominaçóes que retratam com mais precisão a metodologia utilizada, determinando o tipo de pesquisa, 
"histórica, descritiva, participante, etnográfica, fenomenológica etc." (p. 25).

Nessa direção, Betтi ${ }^{32}$ elucida que dados de depoimentos ou observaçóes também podem ser convenientemente expressos em dados numéricos, o que evidencia a importância da superação da dicotomia, bem como as possibilidades de diálogo entre as duas correntes.
Também como parte da análise realizada, apresentamos as figuras com os tipos de pesquisas adotados e seus respectivos quantitativos. Ressaltase que as categorias surgiram a partir da análise das metodologias, classificando-as de acordo com $o$ indicado no texto, portanto, não fizemos uso interpretativo e subjetivo, buscamos seguir o delineamento metodológico assumido pelos autores.

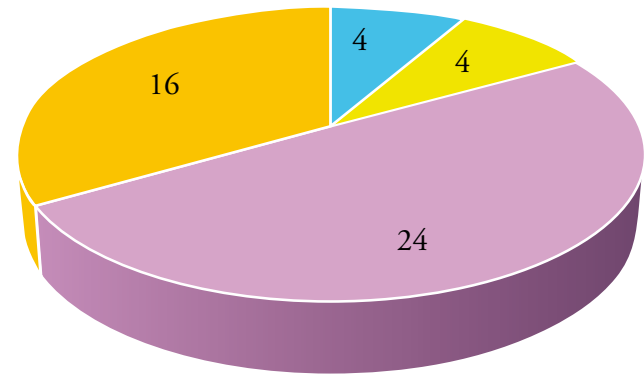

- Exploratória/Descritiva =Exploratória "Descritiva "Não apresentam

FIGURA 2 - Quantitativo por categoria referente aos tipos de pesquisas considerando os objetivos.

Na FIGURA 2 observa-se que nem todas as pesquisas analisadas recorreram ao uso de metodologias considerando seus objetivos (16); 24 são descritivas; 4 são exploratórias; e 4 foram alocadas em duas categorias por empregarem ambas. Já a pesquisa explicativa não foi utilizada por nenhum dos estudos.

Em relação à pesquisa descritiva constitui-se como categoria predominante na elaboração de teses e dissertaçōes (24), tendo como objetivo primordial, segundo $\mathrm{GIL}^{27}$, a descrição das características dos fatos ou fenômenos ou o estabelecimento de relações entre variáveis. Como exemplo desse tipo de pesquisa podemos citar aquelas que têm por objetivo estudar: nível de escolaridade, índice de criminalidade, opiniōes de uma população, pesquisas eleitorais, entre outras ${ }^{27}$.

No que se refere à pesquisa exploratória, esta foi utilizada por 4 teses e dissertaçôes. Este tipo de pesquisa procura trazer à tona a compreensão de temas emergentes, para os quais não temos ainda conhecimento sistematizado, nem bibliografia consolidada. Para tanto, são consultadas pessoas que tenham alguma experiência prática ou teórica relacionada ao tema ${ }^{26}$. Embora o planejamento seja bastante flexível, geralmente assume o formato de pesquisa bibliográfica ou estudo de $\operatorname{caso}^{27}$, o que foi possível observar nesse estudo.
Nesse estudo observou-se também que 4 das teses e dissertações utilizaram a pesquisa descritiva em associação com a exploratória. Isso ocorre especialmente quando as pesquisas descritivas vão além da identificação da existência das relaçôes entre variáveis, buscando proporcionar uma nova visão de determinado problema, o que a faz aproximarse da pesquisa exploratória ${ }^{27}$. Assim, as pesquisas descritivas e exploratórias, de acordo com $\mathrm{GIL}^{27}$ são realizadas habitualmente pelos pesquisadores sociais, sendo também as mais utilizadas pelas instituiçóes educacionais, o que reflete os achados da pesquisa em questão.

De acordo com o pressuposto organizacional de $\mathrm{GIL}^{27}$, os resultados tornam-se preocupantes, visto que 16 teses e dissertaçóes não descrevem o uso de nenhum método considerando o objetivo da pesquisa. Essa lacuna pode ter fundamento na ausência de rigor ou também na ausência de uma padronizaçáo consensual dos requisitos necessários para que seja uma metodologia de alto padrão acadêmico.

$\mathrm{Na}$ continuidade da análise, segue FIGURA 3 contendo os resultados referentes aos tipos de pesquisa considerando os procedimentos técnicos utilizados. Das 48 pesquisas analisadas, 30 aplicaram algum tipo de procedimento técnico, dos quais $36,7 \%$ fizeram uso de mais de um instrumento em simultâneo. 


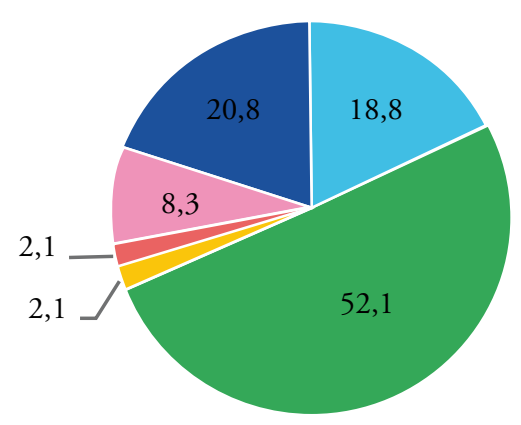

$$
\begin{aligned}
& \text { - Pesquisa bibliográfica - Pesquisa documental - Ex - post facto } \\
& \text { - Pesquisa participante } \quad \text { Estudo de campo - Estudo de de caso }
\end{aligned}
$$

FIGURA 3 - Percentual por categoria referente aos tipos de pesquisas considerando os procedimentos técnicos.

Na FIGURA 3 observa-se a seguinte ordem de predominância: pesquisa documental $(52,1 \%)$, estudo de caso $(20,8 \%)$, pesquisa bibliográfica $(18,8 \%)$, estudo de campo $(8,3 \%)$, ex-post facto e pesquisa participante $(2,1 \%)$.

Em se tratando da pesquisa documental, que se fez presente em $52,1 \%$ das teses e dissertaçôes, $\mathrm{GIL}^{27}$ elucida que se trata de uma investigação que se desenvolve com base em materiais que ainda não receberam um tratamento analítico, sendo diversificadas e dispersas. A pesquisa documental é um importante procedimento metodológico em ciências humanas e sociais e, portanto, da educação. Além do mais, pode ser o principal caminho ou instrumento complementar da pesquisa, dependendo do desenho da mesma ${ }^{37}$.

Uma de suas vantagens é que os documentos podem ser considerados uma fonte rica e estável de dados que subsistem ao longo do tempo, e as informaçóes contidas em documentos possibilitam uma apreensão mais profunda do fenômeno estudado, favorecendo uma melhor visão do problema.

$\mathrm{Neves}^{38}$ advoga que a pesquisa documental é uma das diferentes possibilidades oferecidas pela abordagem qualitativa. Esse tipo de associação possibilita que a interpretação dos dados seja realçada a partir do olhar do investigador. Fato que justifica os dados encontrados nessa pesquisa, visto que as teses e dissertações estudadas fizeram uso dessa associação. Defendemos esta associação entendendo que a abordagem qualitativa não exclui e/ou limita o uso de dados numéricos.

Com relação à pesquisa bibliográfica, utilizada por $18,8 \%$ das teses e dissertaçóes, GIL ${ }^{27}$ aponta que esta é desenvolvida com base em material já elaborado, constituído especialmente por livros e artigos científicos.

Contudo, há algumas problemáticas presentes no processo de escolha destes dois métodos, posto que por vezes a pesquisa documental se confunde com a bibliográfica, pois nem sempre a distinção entre as duas é totalmente evidente. A confusão se dá pelo fato de que a pesquisa bibliográfica pode ser tratada como um tipo de pesquisa documental, uma vez que faz uso de documentos impressos, que na maioria das vezes podem ser utilizados também como bibliográficos. A principal diferença entre a pesquisa bibliográfica e documental recaí sobretudo na natureza das fontes. Enquanto a primeira, tem como essência o uso das contribuiçóes de diversos autores sobre ao assunto, a segunda centra-se em materiais de primeira máo, como por exemplo, cartas, diários, memorandos etc., ou de segunda mão, como dados estatísticos, relatórios de pesquisa e de empresas, entre outros.

Em relação ao estudo de caso como procedimento técnico, este foi utilizado por $20,8 \%$ das teses e dissertaçóes. Triviños ${ }^{39}$, considera o estudo de caso como uma categoria, modalidade, ou um tipo de análise qualitativa que tem como principal característica a profundidade de estudo de uma unidade. Nesse sentido, $\mathrm{GIL}^{27}$ complementa que o estudo de caso é amplamente utilizado nas ciências biomédicas e sociais, e consiste em estudar profunda e exaustivamente um ou poucos objetos.

Cabe mencionar que um bom estudo de caso constitui tarefa difícil de realizar e que necessita de uma boa atuação do pesquisador, que buscará a distinção entre o fenômeno e seu contexto real, que 
por vezes não são claramente percebidos ${ }^{27}$. Pela sua aceitação no contexto educacional, sua utilização tem recebido um sensível crescimento nas últimas décadas, o que pode ser observado nos resultados obtidos, em que se fez presente em 11 de 47 teses e dissertações que constituíram a amostra.

Para além destes procedimentos, também identificamos o estudo de campo $(8,3 \%)$ e expost facto $(2,1 \%)$ e participante $(2,1 \%)$ que foram utilizados pelos pesquisadores com menor frequência.

Ainda vale referir que também identificamos a presença de outras metodologias para além das citadas por $\mathrm{GIL}^{27}$, como comparativa, nãoexperimental, diagnóstica, teoria fundamentada, analítica e interpretativa, entre outras. Contudo, náo foram computadas, uma vez que adotamos um referencial para a classificação e também por não serem utilizadas com um quantitativo expressivo.

Após o mapeamento das características metodológicas, vale pontuar a importância e necessidade das teses e dissertaçóes apresentarem rigor na descrição e escolha dos métodos para melhor compreensáo dos caminhos adotados na elaboração da pesquisa. Observa-se, de forma geral, que as teses e dissertaçóes pesquisadas ainda se apresentam de forma falha quanto aos pressupostos de rigor metodológico exposto por $\mathrm{GIL}^{27}$ em que aponta a necessidade da utilização de três segmentos (objetivos, procedimentos técnicos e abordagem). Os dados apontam que somente 10 dissertaçóes e uma tese seguem essa caracterização metodológica.
Dentre estas pesquisas, outro resultado obtido, diz respeito ao quantitativo de trabalhos propositivos e náo propositivos. As pesquisas foram categorizadas como propositivas porque apresentaram algum tipo de proposição objetivada, podendo ser metodológica, pedagógica, curricular etc. sobre a temática. As pesquisas não propositivas não apresentam aspectos relacionados à intervenção, sendo caracterizadas como diagnósticas, descritivas, de fundamentação teórica.

Foi possível aferir que dentre as 16 teses, $37,5 \%$ são propositivas, constituindo um número substancialmente mais elevado do que os $9,4 \%$, das 32 dissertaçóes. Esse baixo quantitativo pode ser justificado pelo tempo destinado à realizaçáo do mestrado (dois anos). No geral, obtivemos o seguinte resultado da amostra total: $18,8 \%$ foram classificadas como propositivas, sendo 6 teses e 3 dissertaçóes.

Para uma melhor visualização do panorama das teses e dissertaçôes que compóem o rol de pesquisas propositivas, elaboramos o QUADRO 1 contendo informaçóes que serão depois categorizadas e discutidas no QUADRO 2.

Nessa direção, elaboramos um quadro contendo a categorização das propostas identificadas nas teses e dissertaçóes, bem como as subcategorias que compuseram o mapeamento de forma detalhada. As categorias e suas respectivas frequências encontradas nas pesquisas podem ser visualizadas no QUADRO 2. Vale salientar que as propostas das teses e dissertaçóes, em alguns casos, enquadram-se nas duas categorias.

QUADRO 1 - Síntese das teses e dissertações da área da Educação Física consideradas como propositivas

\begin{tabular}{|c|c|c|c|c|}
\hline \multicolumn{5}{|c|}{ TESES } \\
\hline Ano & Autor & Título & IES & Proposta \\
\hline 1998 & Ghirotto, F.M.S. & $\begin{array}{l}\text { Socorros de urgência e a } \\
\text { preparação do profissional } \\
\text { de educação física }\end{array}$ & Unicamp & $\begin{array}{l}\text { Propóe um programa para a disciplina } \\
\text { de socorros de urgência nos cursos } \\
\text { de Educação Física, com vistas a } \\
\text { superar as fragilidades concernentes } \\
\text { ao desenvolvimento desse conteúdo, } \\
\text { bem como suprir as demandas da } \\
\text { atuação profissional }\end{array}$ \\
\hline 2002 & Ramos, G.N.S. & $\begin{array}{l}\text { Preparação profissional em } \\
\text { Educação Física: a questão } \\
\text { dos estágios }\end{array}$ & Unicamp & $\begin{array}{l}\text { Aponta possibilidades para o } \\
\text { desenvolvimento dos estágios } \\
\text { curriculares no processo de preparação } \\
\text { profissional em Educaçáo Física, } \\
\text { valendo-se do aporte teórico do ensino } \\
\text { reflexivo }\end{array}$ \\
\hline
\end{tabular}


QUADRO 1 - Síntese das teses e dissertações da área da Educação Física consideradas como propositivas

\begin{tabular}{|c|c|c|c|c|}
\hline \multicolumn{5}{|c|}{ TESES } \\
\hline Ano & Autor & Título & IES & Proposta \\
\hline 2002 & Isayama, H.F. & $\begin{array}{l}\text { Recreação e lazer como } \\
\text { integrantes dos currículos } \\
\text { dos cursos de graduação } \\
\text { em Educaçáo Física }\end{array}$ & Unicamp & $\begin{array}{l}\text { Aponta subsídios para uma organização } \\
\text { curricular que contemple a formaçáo de } \\
\text { profissionais dentro da perspectiva do } \\
\text { animador sociocultural }\end{array}$ \\
\hline 2005 & $\begin{array}{l}\text { Barbosa-Rinaldi, } \\
\text { I.P. }\end{array}$ & $\begin{array}{l}\text { A ginástica como área de } \\
\text { conhecimento na formação } \\
\text { profissional em Educação } \\
\text { Física: encaminhamentos } \\
\text { para uma estruturação } \\
\text { curricular }\end{array}$ & Unicamp & $\begin{array}{l}\text { Apresenta uma proposta de } \\
\text { estruturaçáo da área de conhecimento } \\
\text { da Ginástica para os currículos dos } \\
\text { cursos de Educação Física, tomando } \\
\text { por base os achados empíricos da } \\
\text { pesquisa, as diretrizes curriculares e o } \\
\text { referencial teórico da epistemologia da } \\
\text { prática reflexiva }\end{array}$ \\
\hline 2005 & Lima, S.M.T. & $\begin{array}{l}\text { Educação Física } \\
\text { Adaptada: proposta de } \\
\text { ação metodológica para } \\
\text { formação universitária }\end{array}$ & Unicamp & $\begin{array}{l}\text { Apresenta uma proposta de ação } \\
\text { metodológica para o desenvolvimento } \\
\text { da disciplina de adaptada no processo } \\
\text { formativo em Educação Física, valendo- } \\
\text { se do aporte teórico da epistemologia } \\
\text { da prática reflexiva }\end{array}$ \\
\hline 2008 & Ehrenberg, M.C. & $\begin{array}{l}\text { Os currículos de } \\
\text { licenciatura em Educação } \\
\text { Física: a dança em questão }\end{array}$ & Unicamp & $\begin{array}{l}\text { Apresenta uma proposta de estruturação } \\
\text { da área de conhecimento da Dança } \\
\text { para os currículos de licenciatura em } \\
\text { Educaçáo Física, construída a partir dos } \\
\text { limites e possibilidades dos resultados } \\
\text { empíricos da pesquisa }\end{array}$ \\
\hline \multicolumn{5}{|c|}{ DISSERTAÇÓES } \\
\hline Ano & Autor & Título & IES & Proposta \\
\hline 1997 & Freitas, P.S. & $\begin{array}{l}\text { O ensino de basquetebol } \\
\text { sobre rodas: desafios e } \\
\text { possibilidades }\end{array}$ & Unicamp & $\begin{array}{l}\text { Propóe orientações metodológicas para } \\
\text { ensino da modalidade basquetebol } \\
\text { sobre rodas nos cursos de formação } \\
\text { inicial em Educaçáo Física }\end{array}$ \\
\hline 2002 & Braga, J.M.P. & $\begin{array}{l}\text { Elementos musicais a } \\
\text { serem abordados na } \\
\text { formação profissional em } \\
\text { Educação Física }\end{array}$ & Unicamp & $\begin{array}{l}\text { Apresenta sugestôes metodológicas para } \\
\text { a aplicação de conhecimentos musicais } \\
\text { na estruturação curricular dos cursos } \\
\text { de formação profissional em Educação } \\
\text { Física }\end{array}$ \\
\hline \multicolumn{5}{|c|}{ DISSERTAÇÔES } \\
\hline Ano & Autor & Título & IES & Proposta \\
\hline 2003 & David, N.A.N. & $\begin{array}{l}\text { Novos ordenamentos legais } \\
\text { e a formação de professores } \\
\text { de Educação Física: } \\
\text { pressupostos de uma nova } \\
\text { pedagogia de resultados }\end{array}$ & Unicamp & $\begin{array}{l}\text { Sugere possibilidades de intervenção } \\
\text { crítica para o processo formativo de } \\
\text { professores de Educação Física }\end{array}$ \\
\hline
\end{tabular}


QUADRO 2 - Categorização das propostas presentes nas teses e dissertações

\begin{tabular}{|l|l|c|}
\hline Categorias & \multicolumn{1}{c|}{ Subcategorias } & $\boldsymbol{f}$ \\
\hline \multirow{5}{*}{$\begin{array}{l}\text { Orientação } \\
\text { técnico-pedagógica }\end{array}$} & $\begin{array}{l}\text { - Orientação metodológica para o ensino; } \\
\text { - Sugestóes metodológicas para a aplicação de atividades; } \\
\text { - Orientação pedagógica para o ensino; } \\
\text { - Proposta metodológica para a área de adaptada com base na } \\
\text { epistemologia da prática reflexiva; } \\
\text { - Orientaçóes didático-pedagógicas para o trato com o conhecimento } \\
\text { gímnico na formação de professores. }\end{array}$ & 5 \\
\hline Organização curricular & $\begin{array}{l}\text { - Estabelecimento de concepçóes sobre organização curricular; } \\
\text { - Proposta curricular para disciplina de socorros de urgência; }\end{array}$ & $\begin{array}{l}\text { - Proposta curricular para os estágios curriculares supervisionados com } \\
\text { base na epistemologia da prática reflexiva; } \\
\text { - Propostas de eixos temáticos para a área do lazer; } \\
\text { - Proposta de estruturação curricular para a área da ginástica nos cursos } \\
\text { licenciatura e bacharelado; } \\
\text { - Proposta de estruturação curricular para a área da dança nos cursos de } \\
\text { licenciatura. }\end{array}$ \\
\hline
\end{tabular}

Seguindo a análise dos dados, o QUADRO 2 contempla a categorização das propostas presentes nas teses e dissertaçôes analisadas. Como resultado, encontramos as categorias orientação técnicopedagógica e organização curricular, as quais agrupam subcategorias que demonstram de forma específica as proposiçóes encontradas nos trabalhos. Em linhas gerais, as pesquisas analisadas apresentam discussões e reflexōes acerca da formação inicial em Educação Física. Estas englobam aspectos históricos, sociais e políticos que influenciaram sua implantação no país; incorporação de parâmetros normativos e a regulamentação da profissão; fragilidades da formação inicial que implicam na atuação profissional; e questionamentos atrelados à necessidade de reformulaçóes das propostas pedagógicas dos cursos a partir da análise da estrutura curricular.

As teses e dissertaçôes que compóem a categoria orientação técnico-pedagógica apresentam encaminhamentos metodológicos para a concretização da prática pedagógica no âmbito da Educação Física. Nas três primeiras subcategorias (orientaçáo metodológica para o ensino, sugestóes metodológicas para a aplicação de atividades e orientação pedagógica para o ensino) são considerados aspectos referentes à importância da motivação para a prática esportiva, diagnóstico do público alvo, domínio de conteúdo, metodologias e recursos utilizados para aplicação de atividades e parâmetros para a execução de técnicas específicas, apresentando conhecimentos teóricos básicos que visam dar suporte à ação interventiva dos futuros profissionais.

A produção do conhecimento da área demonstra a recorrente preocupação com o papel da Educação Física escolar, sobretudo, quando a partir da década de 1980 se intensifica a influência das ciências humanas neste contexto. Daí a busca pela superação da lógica racional presente nos conteúdos e nas metodologias tradicionais de ensino, para que a prática pedagógica não se resuma ao ensino de técnicas esportivas, mas contribua efetivamente para a formação dos sujeitos. As preocupaçóes apontam também para a necessidade da aproximação da produção científica com as problemáticas cotidianas da profissão, vinculadas às emergentes transformaçôes sociais e aos vertiginosos avanços da ciência e tecnologia, que influem diretamente no universo educacional.

De acordo com Proni ${ }^{40}$ no cenário de democratização das práticas e políticas sociais, o ensino da Educação Física no Brasil passou por um processo de reestruturaçáo curricular, que redefiniu seus conteúdos e métodos de ensino, respaldado pelo avanço da produção do conhecimento e pela busca de mais autonomia como área de formação profissional. Por outro lado, Freire, Verenguer e ReIs ${ }^{41}$ destacam que as produçóes teóricas ainda precisam avançar para que possam contribuir efetivamente com as constantes transformaçóes no campo de atuação profissional, com vistas a um permanente repensar acerca da prática interventiva, para que métodos e técnicas conexos com as problemáticas da profissão sejam adotados. 
Já as subcategorias, proposta metodológica para a área de adaptada com base na epistemologia da prática reflexiva e orientaçóes didático-pedagógicas para o trato com o conhecimento gímnico na formação de professores, apresentam indicaçóes acerca da superação da racionalidade técnica. Demonstram ainda, preocupação com uma visão integral do humano, importância de romper com as relaçóes autoritárias entre professor e aluno, papel do professor no processo formativo, importância da adoção de uma prática reflexiva no trabalho pedagógico, tendo o docente como sujeito que reflete sobre a própria prática pedagógica, com um desenvolvimento contínuo dos saberes.

Nota-se, de forma geral, que as pesquisas assinalam para uma nova perspectiva para a formaçáo inicial dos professores, cuja finalidade é enriquecer e ampliar os horizontes das açóes desenvolvidas. Sobre essa perspectiva, Caldeira ${ }^{42}$ expóe que as concepções atuais apontam a importância de ultrapassar o entendimento fragmentário dos conhecimentos que permeavam a formação inicial, delineando-se novos pontos de vista, que pontuam e valorizam o conhecimento do professor, em um processo interativo e reflexivo. Destaca-se que essa nova concepção pode contribuir para a compreensão da relação teoria e prática, a partir do próprio fazer/refletir docente.

Encontramos em FenSTERSEIFER ${ }^{43}$ indicações sobre a relação estabelecida entre a reflexão epistemológica e a prática pedagógica na Educação Física, açáo considerada como indispensável para o avanço na área no sentido de ultrapassar os limites das questóes instrumentais, técnicas e metodológicas.

Vale salientar que as pesquisas analisadas indicam proposiçóes acerca da organização curricular e trato pedagógico no âmbito da Educação Física, tomando por base a epistemologia da prática reflexiva. Pimenta $^{44}$ afirma que, no Brasil, as contribuiçóes relativas ao conceito do professor reflexivo, trazidas por autores estrangeiros, nos anos de 1990, como Schön, Pérez Gómez, Zeichner, Marcelo García, Elliott, Nóvoa, entre outros, foram acolhidas porque traziam perspectivas para a reinvenção da escola democrática.

A segunda categoria (organização curricular) agrupa as subcategorias: concepçóes sobre a organização curricular, proposta curricular para disciplina de socorros de urgência, proposta curricular para os estágios curriculares supervisionados com base na epistemologia da prática reflexiva, eixos temáticos para a área do lazer, estruturação curricular para a área da ginástica nos cursos licenciatura e bacharelado e estruturação curricular para a área da dança nos cursos de licenciatura. Destacamos as discussóes e proposições sobre a concepção de currículo, qual seja holística e integradora, a elaboração do projeto político pedagógico que pressuponha a participação coletiva dos envolvidos no processo, a necessidade de buscar uma preparaçáo profissional crítica e reflexiva, e a organização sistemática de conhecimentos a serem contemplados na formaçáo inicial.

A produção teórica sobre currículo apresentada por autores como Apple ${ }^{45}$, Gimeno SACRISTÁN ${ }^{46}$, entre outros, expóe uma visão crítica acerca da sua constituição nos contextos em que são consolidados, apontando para a necessidade de compreensão das relaçóes estabelecidas e das suas formas de institucionalização, com vistas a superar a concepçáo puramente burocrática e racional de ordenamento do ensino. Vale destacar o reconhecimento do desenvolvimento curricular como um processo em constante e pleno desenvolvimento.

O foco no planejamento coletivo foi tratado por Veiga ${ }^{47}$, Catani e Gutierrez ${ }^{48}$, Ghedin ${ }^{49}$, Acioli $^{50}$ e Gimeno SaCristán ${ }^{46}$ em produçóes que lançam mão da elaboração coletiva do planejamento pedagógico como ação indispensável para resultados efetivos na prática educacional. Já o embate que se trava acerca da Educação Física como componente curricular obrigatório, bem como a seleção adequada dos conteúdos trabalhados nessa disciplina tem sido amplamente estabelecido ao longo dos anos ${ }^{51,52}$.

Por fim, entendemos que por meio dos achados nesta pesquisa foi possível construir um banco de dados que proporcionou um panorama geral da produção de conhecimento sobre formação inicial e currículo na Educação Física, tendo como lócus de investigação os programas de pós-graduação da área em questão. $\mathrm{O}$ material coletado ainda poderá ser utilizado para a realizaçáo de outras pesquisas com diferentes enfoques, com vistas a contribuir para o avanço acadêmico da área.

A partir do mapeamento coletado, entendemos que a produção científica (dissertaçóes e teses) na área da Educação Física é caracterizada por estudos não propositivos que adotam em sua maioria um desenho metodológico com abordagem qualitativa, descritiva, documental e estudo de caso, que por vezes se associaram para alcançar os objetivos propostos. As pesquisas propositivas apareceram com quantitativo menos expressivo, sendo mais numerosas entre as teses do que dissertaçóes, fato que pode estar relacionado ao 
tempo disponibilizado para participação nos programas de pós-graduaçáo (mestrado 2 anos e doutorado 4 anos).

Dentre as pesquisas propositivas, surgiram duas categorias: orientação técnico-pedagógica e organização curricular. A primeira mais relacionada às propostas sobre orientaçóes metodológicas, didáticas e pedagógicas direcionadas ao trato com o conhecimento da Educação Física, sendo ele específico ou não. A segunda refere-se à elaboração curricular, como propostas de programas disciplinares e eixos temáticos.

No que se refere ao volume da produção sobre formação inicial e currículo, este apresentou pouca representatividade, principalmente quando comparamos com a amostra total de teses e dissertaçóes. Entretanto, quanto ao fluxo de produção a linha de tendência, de maneira geral, apresentou-se de forma crescente, recebendo um alto índice em 2002 seguido de queda brusca no ano seguinte.

Se faz importante indicar que não intentamos estabelecer discussóes acerca dos programas de pósgraduação que apresentam ou não produçóes acerca da temática, esta análise pode constituir pesquisas futuras que indiquem possíveis lacunas no tocantes relacionadas às produçóes de teses e dissertaçōes de acordo com os programas de pós-graduação do país, bem como mapear o número de defesas realizadas por ano em cada um deles.

No entanto, mesmo tendo indicaçóes para pesquisas futuras, apontamos que estas representam as limitaçóes dessa pesquisa, juntamente com: não atualização dos sites, possibilitando-nos a elaboração de um banco de dados relativo, composto pelas produçóes encontradas online. Porém, analisamos que os dados aqui tratados indicam o cenário que a maior parte do universo acadêmico tem acesso, além de revelar dados que podem contribuir para o entendimento da configuraçáo da área no que concerne o processo formativo.

Ainda, indicamos como possível lacuna referente às pesquisas analisadas, a necessidade de desenvolvimento de teses e dissertaçóes que foquem, a formação inicial e currículo, após as mudanças curriculares pela qual a área passou, considerando seu impacto para a área como um todo. Este indicativo toma como base o curto espaço temporal entre o ano de 2006 (data limite para implantaçáo dos currículos para atender a legislação vigente ${ }^{28,29,52}$ ) e o período analisado.

Vale ressaltar que não fizemos uso das teses e dissertações dos programas de pós-graduação da área da Educação, pois o objetivo estava relacionado com o mapeamento do estado da arte das pesquisas realizadas nos programas da Educação Física. Contudo, indicamos que pesquisas futuras poderão recorrer a esta fonte de dados.

Para finalizar, entendemos que pesquisas deste tipo subsidiam a compreensão do estado da arte sobre temas específicos e relevantes para a área da Educação Física, uma vez que permitem visualizar o panorama do que vem sendo estudado/investigado pelos pesquisadores.

\section{Abstract}

\section{The production of knowledge about training and curriculum in Physical Education in Brazil}

This bibliographic research aimed to analyze the production of knowledge through theses and dissertations about training and curriculum in physical education in the period 1980-2012, with a view to mapping the methodological characteristics as well as the propositions for the training scenario. The sample consisted of 47 research, 15 theses and 32 dissertations, analyzed through descriptive statistics and content analysis. These studies represent only $2 \%$ of the total sample of theses and dissertations. Verified that the qualitative approach, case study and the descriptive and documentary research, were used more frequently. The results also indicate that $83 \%$ of researches are not propositional and 17\% propositional, these being represented by two categories: technical and pedagogical guidance and curriculum organization. We conclude that there is necessity of development of theses and dissertations that focus be the initial training and curriculum, especially when considering the curricular changes and their impact on the area as a whole, as well as highlight the importance of scientific production with propositional character to the area of physical education.

KEYwORDS: Training; Knowledge; Research; Methodology. 


\section{Referências}

1. Verenguer RCG. Preparação profissional em Educação Física: das leis à implementação dos currículos [dissertação]. Campinas (SP): Universidade Estadual de Campinas, Faculdade de Educação Física; 1996.

2. Anderáos M. A formação profissional na Faculdade de Educação Física de Santo André- manutenção ou alteração [dissertação]. Campinas (SP): Universidade Estadual de Campinas, Faculdade de Educação Física; 1998.

3. Barbosa-Rinaldi IP. A ginástica nos cursos de licenciatura em educação física do estado do Paraná [dissertação]. Campinas (SP): Universidade Estadual de Campinas, Faculdade de Educação Física; 1999.

4. Moreira EC. Licenciatura em Educação Física: reflexos dessa formaçáo na regiáo do grande $A B C$ [dissertação]. Campinas (SP): Universidade Estadual de Campinas, Faculdade de Educaçâo Física; 2002.

5. Schwarz L. A disciplina lazer e recreação na formação de professores de Educação Física: estudo sobre alguns tratos curriculares em universidades estaduais do Paraná [dissertação]. Florianópolis (SC): Universidade Federal de Santa Catarina, Centro de Desportos; 2007.

6. Brugnerotto FA. Caracterização dos currículos de formação profissional em Educação Física: um enfoque sobre saúde [dissertaçāo]. Piracicaba (SP): Universidade Metodista de Piracicaba, Faculdade de Ciências da Saúde; 2008.

7. Carvalho LP. Projeto político-pedagógico, diretrizes curriculares e o embate epistemológico na formação inicial em Educaçáo Física: um estudo na regiáo oeste do Paraná [dissertaçâo]. Florianópolis (SC): Universidade Federal de Santa Catarina, Centro de Desportos; 2009.

8. Pizani J. A formação inicial em Educação Física no Estado do Paraná e o perfil dos cursos de licenciatura e bacharelado [dissertação]. Maringá (PR): Universidade Estadual de Maringá, Centro de Ciências da Saúde; 2011.

9. Ramos GNS. Preparação profissional em Educação Física: a questão dos estágios [tese]. Campinas (SP): Universidade Estadual de Campinas, Faculdade de Educação Física; 2002.

10. Anderáos M. A reorganização da formação profissional em Educação Física no Brasil: aspectos históricos significativos [tese]. Campinas (SP): Universidade Estadual de Campinas, Faculdade de Educação Física; 2005.

11. Barbosa-Rinaldi IP. A ginástica como área de conhecimento na formação profissional em Educaçáo Física: encaminhamentos para uma estruturação curricular [tese]. Campinas (SP): Universidade Estadual de Campinas, Faculdade de Educação Física; 2005.

12. Souza NP. O ensino das disciplinas esportivas coletivas nos cursos de licenciatura em Goiás: um estudo descritivo [tese]. Campinas (SP): Universidade Estadual de Campinas, Faculdade de Educação Física; 2007.

13. Antunes AC. A dimensão prática na preparação profissional em Educação Física: concepção e organização acadêmica [tese]. Campinas (SP): Universidade Estadual de Campinas, Faculdade de Educaçâo Física; 2012.

14. Fensterseifer PE. Educação Física: atividade epistemológica e objetivismo. Filos Educ. 2010;2(2):99-110.

15. Bracht V, Faria BA, Almeida FQ, et al. A Educação Física Escolar como tema da produçáo do conhecimento nos periódicos da área no Brasil (1980-2010): parte I. Movimento. 2011;17(2):11-34.

16. Daolio J. Educaçâo Física brasileira: autores e atores da década de 80 [tese]. Campinas (SP): Universidade Estadual de Campinas, Faculdade de Educação Física; 1997.

17. Brasil. Congresso Nacional. Lei no 5.692, de 11 de agosto de 1971. Fixa diretrizes e bases para o ensino de $1^{\circ} \mathrm{e} 2^{\circ}$ graus, e dá outras providências. Diário Oficial da Uniâo. 12 ago 1971;1:6377.

18. Lüdorf SMA. Panorama da pesquisa em Educação Física da década de 90: análise dos resumos de dissertaçóes e teses. Rev Educ Fís UEM. 2002;13(2):19-25.

19. Souza e Silva RV. Mestrados em Educação Física no Brasil: pesquisando suas pesquisas [dissertação]. Santa Maria (RS): Universidade Federal de Santa Maria, Centro de Ciências da Saúde e do Esporte; 1990.

20. Souza e Silva RV. Pesquisa em Educação Física: determinaçóes históricas e implicaçôes epistemológicas [tese]. Campinas (SP): Universidade Estadual de Campinas, Faculdade de Educação; 1997.

21. Kokubun E. Pós-Graduaçáo em Educaçáo Física no Brasil: indicadores objetivos dos desafios e das perspectivas. Rev Bras Ciênc Esporte. 2003;24(2):9-26.

22. Botomé SP, Kubo OM. Responsabilidade social dos programas de pós-graduação e formação de novos cientistas e professores de nível superior. Inter Psicol. 2002;6(1):81-110.

23. Carlan P. A produção do conhecimento na Educação Física brasileira e sua proposta de intervençẫo na Educação Física escolar [dissertação]. Florianópolis (SC): Universidade Federal de Santa Catarina; 1996.

24. Molina Neto V, Günther MCC, Bossle F, Wittizorecki ES, Molina RSK. Reflexões sobre a produção do conhecimento em Educação Física e ciências do esporte. Rev Bras Ciênc Esporte. 2006;28(1):145-65. 
25. Trujillo Ferrari A. Metodologia da pesquisa científica. São Paulo: McGraw-Hill do Brasil; 1982.

26. Bardin L. Análise de conteúdo. Lisboa: Ediçóes 70; 1977.

27. Gil AC. Como elaborar projetos de pesquisa. 5a ed. São Paulo: Atlas; 2010.

28. Brasil. Conselho Nacional de Educação. Conselho Pleno. Resoluçáo CNE/CP no 1, de 18 de fevereiro de 2002. Institui diretrizes curriculares nacionais para a formação de professores da educação básica, em nível superior, curso de licenciatura, de graduação plena. Diário Oficial da União. 9 abr 2002;1:31.

29. Brasil. Conselho Nacional de Educação. Conselho Pleno. Resolução CNE/CP no 2, de 19 de fevereiro de 2002. Institui a duração e a carga horária dos cursos de licenciatura, de graduação plena, de formação de professores da educação básica em nível superior. Diário Oficial da União. 4 mar 2002;1:9.

30. Coordenação de Aperfeiçoamento de Pessoal de Nível Superior. Geocapes - Sistema de Informações Georreferenciadas | Capes [Internet]. Brasília: Capes; 2009 [citado 29 jul 2019]. Disponível em: http://geocapes.capes.gov.br.

31. Gomes PMS, Ferreira CPP, Pereira AL, Batista PMF. A identidade profissional do professor: um estudo de revisão sistemática. Rev Bras Educ Fís Esporte. 2013;27(2):247-67.

32. Betti M. Educação Física escolar: ensino e pesquisa-ação. 2a ed. Ijuí: Editora Unijuí; 2013.

33. Bogdan RC, Biklen SK. Investigação qualitativa em educação. Porto: Porto Editora; 1994.

34. Thomas J, Nelson JK. Métodos de pesquisa em atividade física. Porto Alegre: Artmed; 2002.

35. André MEDA. Texto, contexto e significados: algumas questóes na análise de dados qualitativos. Cad Pesq. 1983;45:66-71.

36. André MEDA. Etnografia da prática escolar. Campinas: Papirus; 1995.

37. Sá-Silva JR, Almeida CD, Guindane JF. Pesquisa documental: pista teóricas e metodológicas. Rev Bras Hist Ciênc Soc. 2009;1(1):1-14.

38. Neves JL. Pesquisa qualitativa: características, usos e possibilidades. Cad Pesq Admin. 1996;1(3):2-5.

39. Triviños ANS. A pesquisa qualitativa em educação. São Paulo: Atlas; 1987.

40. Proni MW. Universidade, profissão Educação Física e o mercado de trabalho. Motriz. 2010;16(3):788-98.

41. Freire ES, Verenguer RCG, Reis MCC. Educação Física: pensando a profissão e a preparação profissional. Rev Mack Educ Fís Esporte. 2002;1(1):39-46.

42. Caldeira AMS. A formação de professores de Educação Física: quais saberes e quais habilidades? Rev Bras Ciênc Esporte. 2001;22(3):87-103.

43. Fensterseifer PE. A Educação Física na crise da modernidade. Ijuí: Editora Unijuí, 2001.

44. Pimenta SG. Professor reflexivo: construindo uma crítica. In: Pimenta SG, Ghedin E. Professor reflexivo no Brasil: gênese e crítica de um conceito. Sáo Paulo: Cortez; 2002. p. 17-52.

45. Apple MW. Ideologia e currículo. 3a ed. Porto Alegre: Artmed; 2006.

46. Gimeno Sacristán J, organizador. Saberes e incertezas sobre o currículo. Porto Alegre: Penso; 2013.

47. Veiga IPA. Projeto político-pedagógico da escola: uma construçáo possível. 11a ed. Campinas: Papirus; 1995.

48. Catani AM, Gutiérrez GL. Participação e gestão escolar: conceitos e potencialidades. In: Ferreira NSC. Gestáo democrática da educação: atuais tendências, novos desafios. São Paulo: Cortez; 1998.

49. Ghedin EL. Professor reflexivo: da alienação da técnica à autonomia da crítica. In: Pimenta SG, Ghedin E. Professor reflexivo no Brasil: gênese e crítica de um conceito. 4a ed. São Paulo: Cortez; 2006.

50. Acioli S. A prática educativa como expressão do cuidado em Saúde Pública. Rev Bras Enferm. 2008;61(1):117-21.

51. Barroso ALR, Darido SC. A pedagogia do esporte e as dimensóes dos conteúdos: conceitual, procedimental e atitudinal. Rev Educ Fís UEM. 2009;20(2):281-9.

52. Palma APTV, Oliveira AAB, Palma JAV, organizadores. Educação Física e a organização curricular: educação infantil, ensino fundamental e ensino médio. 2a ed. Londrina: Eduel; 2010.

53. Brasil. Conselho Nacional de Educação. Câmara de Educação Superior. Resoluçáo no 7, de 31 de março de 2004. Institui as diretrizes curriculares nacionais para os cursos de graduação em Educação Física, em nível superior de graduação plena. Diário Oficial da União. 5 abr 2004;1:18.

ENDEREço
Juliana Pizani
Rua Eng. Agronômico Andrei Cristian Ferreira,
s/n - Trindade - 88040-9oo
Florianópolis - SC - BRASIL
e-mail: jupizani@hotmail.com;
parrarinaldi@hotmail.com

Recebido para publicação: 22/04/2015

$1^{a}$. Revisão: 30/05/2016

$2^{\text {a }}$. Revisão: $11 / 01 / 2018$

Aceito: 07/03/2018 